\title{
Aviation To-day
}

\section{And the Importance of a National Aerodynamic Laboratory}

\section{By Capt. W. Irving Chambers, U. S. Navy}

INFLUENCE OF FOREIGN LA ORATORIES.

LIITLE more than a year ago our knowledge of the effect of air currents upon aeroplane surfaces was almost entirely a matter of theory. The exact information available was so meager that aeroplanes were built either as copies, slightly modified, of other machines, or else by way of haphazard experiment. This state of affairs obtains to some extent in the United State t)-day, although in Europe aeroplane construction is now largely based on scientific data obtained at notable aerodynamic laboratories.

The intuitive, hasty, and crude methods of the pionee cannot succeed in competition with the accurate and systematic methods of the scientific engineer, and it is beginning to dawn upon our perceptions that through lack of preparation for the work of the scientific engineer, i. e., through delay in establishing an aerodynamic laboratory, a waste of time and money, a decline of prestige, and an unnecessary sacrifice of human life already resulted.

Students of aviation do not need to be informed of the practical necessity for aerodynamic laboratories. They have repeatedly pointed out, in aeronautical publications, the immense commercial advantages to be anticipated from the establishment of at least one in this country, and they have naturally expected that some philanthropic patriot of wealth and scientific some philanthr interest would cone to the rescue with a suitable endowin short order without Government aid. The fact that no patriot has responded is disappointing in view of the large private donations that have done so much for aviation in France; but, in my opinion, it simply indicates something lacking in the manner of disseminating information concerning the importance of the nating information concerning the importance of the will refuse to establish one when they are fully acquainted with the advantages to humanity and to san industrial progress, and when a reasonable concrete proposition is advanced for their consideration. I have submitted such a proposition as follows, being guided in general outline by the ideas advanced in an address to the Fifth International Aeronautic Congress by one of the greatest authorities in the world, the Commandan of the greatest authorities in the world, the Commandant
Paul Renard, president of the International Aeronautic Commission.

AL AERODYNAMIC LABORATORY.

The work done by Prof. Langley at the Smithsonian Institution, in a brief period, over sixteen years ago, with meager resources and little encouragement, by means with meager resources and little encouragement, by means Army, was such a valuable contribution to the science of aeronautics that the United States, even to-day, is credited abroad with possessing a real aerodynamic laboratory. I fancy there are people in this country who believe that the work inaugurated by Langley is still proceeding in a systematic way, but it is unfortunate that his work was not permitted to expand and to develop that his work was not permitted to expand and to deve
into one of the first national institutions of this kind.

The first of the modern laboratories was that of the F'rench Military Establishment at Chalais, and now the laboratories of the Italian specialist brigade in Rome,

* This article, for which we are indebted to Flying, is the ber 21 st, 1912 .

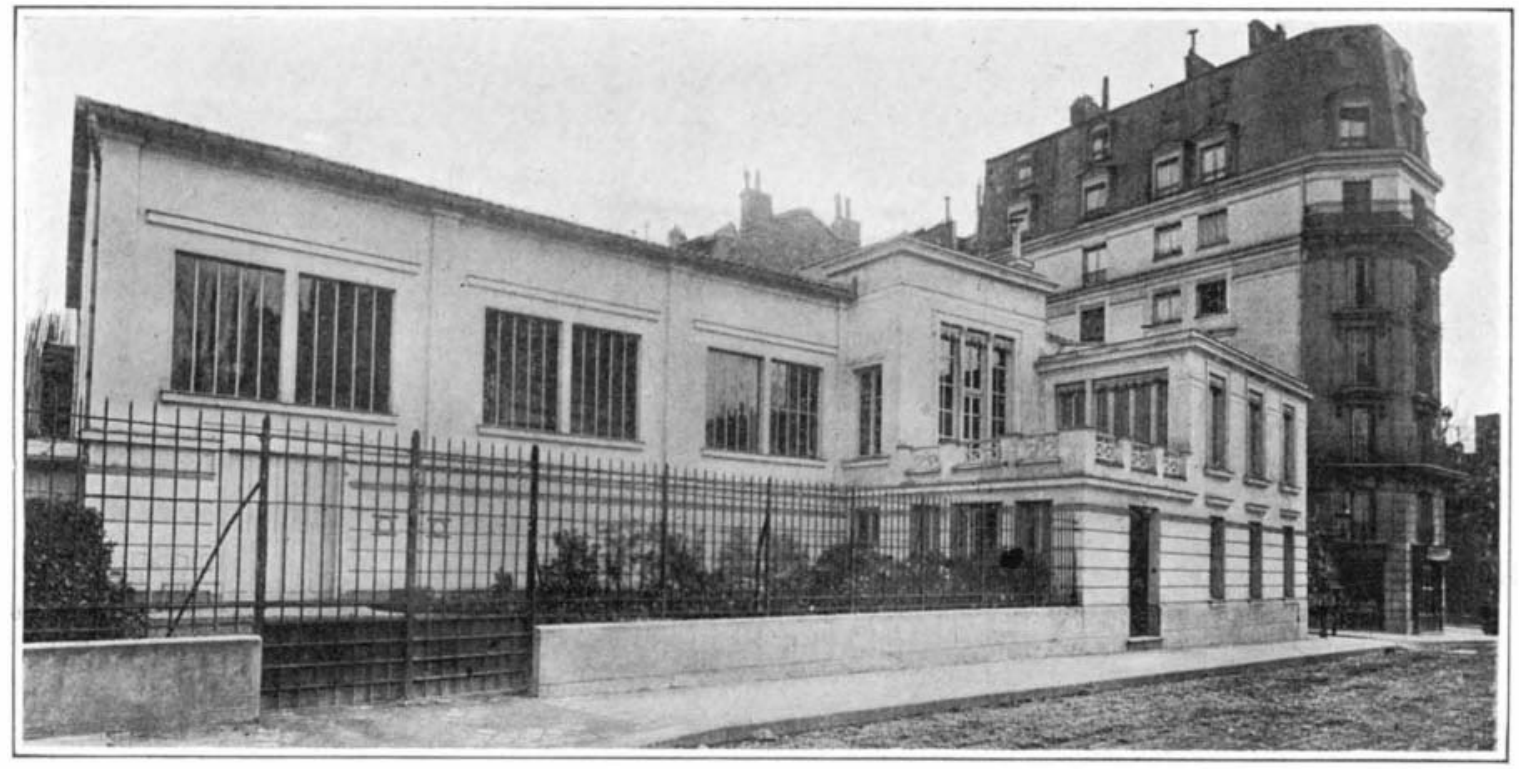

The Eiffel Aerodynamic Laberatory at Auteuil, Near Paris in order that appliances specially needed in the new work may be provided, and that these

For the sake of economy, not only of money, but of time and intellectual energy, tests and experiments that can be executed as well or better elsewhere by existing establishments should be avoided. For exexisting establishments should be avoided. For ex-
ample, it is unnecessary to install a complete set of instruments and implements for testing the tensile strength of materials or their bending and crushing strength. Many other establishments permit of such work. If the laboratory be located in Washington, work. If the labora readily done at the navy yard, where other facilities readily done at the navy yard, where other facilities
exist, such, for instance, as the testing of models for hydroaeroplanes or flying boats. The Bureau of Standards and Measures, and other Government branches in Washington, also offer facilities which it would not be wise to duplicate in such a laboratory.

I do not think that such an institution should be burdened with measuring the power of motors, or preoccupied with the details of their performances. This may be done at various other Government establishments, and it is understood that the Automobile Club of America is also equipped for this work.

Nor is it necessary to have a complete chemical laboratory under the pretext of studying questions relating to the chemistry of fuel, or the permeability relating to the chen
of balloon envelopes.

I do not wish to convey the idea that an aerodynamic laboratory should be deprived entirely of such facilities, and that it should be obliged to seek minor information from other establishments when that information may be more economically obtained by a duplicate plant on a small scale. Such duplicate conveniences, hlant on a small scale. Such duplicate conveniences, it should be well understood that, whenever important researches can be prosecuted as well or better elsewhere, dependence should be placed on those other establishments where such work is a specialty. TWO DISTINCT CLASSES OF WORK. An aerodynamic laboratory should be devoted to
(1) experimental verification, (2) experimental research. The first is concerned with testing the qualities of existing appliances, propellers, sustaining surfaces, control mechanism, etc. Usually these tests are made at the request of interested parties (as is now the case with water models at the Navy Yard Model Basin). A constructor or a designer will bring, for example, a propeller, and will wish to know its power or thrust at a given speed on the block, or on a moving appliance under the conditions of flight, or he may bring several propellers to compare their performances, and to ascertain what power they absorb at different speeds.

One of the very successful appliances devoted to this work at St. Cyr is a movable car in which an aeroplane may be mounted and tested at speeds, in perfect safety, as to its strength, its efficiency, and the suitability of its control mechanism. This device is specially adapted to make actual service tests of sustaining surfaces, in other words, to try out, in perfect safety, the relative efficiencies of finished aeroplanes. It is a most important adjunct, as it supplements and rounds out the important research work on models in the closed laboratory.

Tests of this character, i. e, verification tests, constitute, so to speak, standard work. They are performed at the request of manufacturers, clubs, independent investigators, and other interested parties on condition of payment for the actual cost of the work. They, therefore, contribute to the support of the establishment.

The tests of verification, however, notwithstanding their great utility, do not constitute either the most important or the most interesting work of the laboratory. The research work, which prosecutes continuously and patiently systematic, thorough, and precise investigation of new ideas, or of old ideas with new applications, with the specific intention of discovering laws and formulas for advancing the progress of aerial navigation, is of greater importance, because it is the short cut to substantial efficiency, economy, improvement, and prestige.

This work is concerned with developing adequate methods of research in all branches of aerial navigation, and in furnishing reliable information to all students, engineers, inventors, manufacturers, pilots, navigators, strategists, and statesmen. The knowledge thus gained should be disseminated regularly through publications, lectures, open-air demonstrations, and by exhibitions 


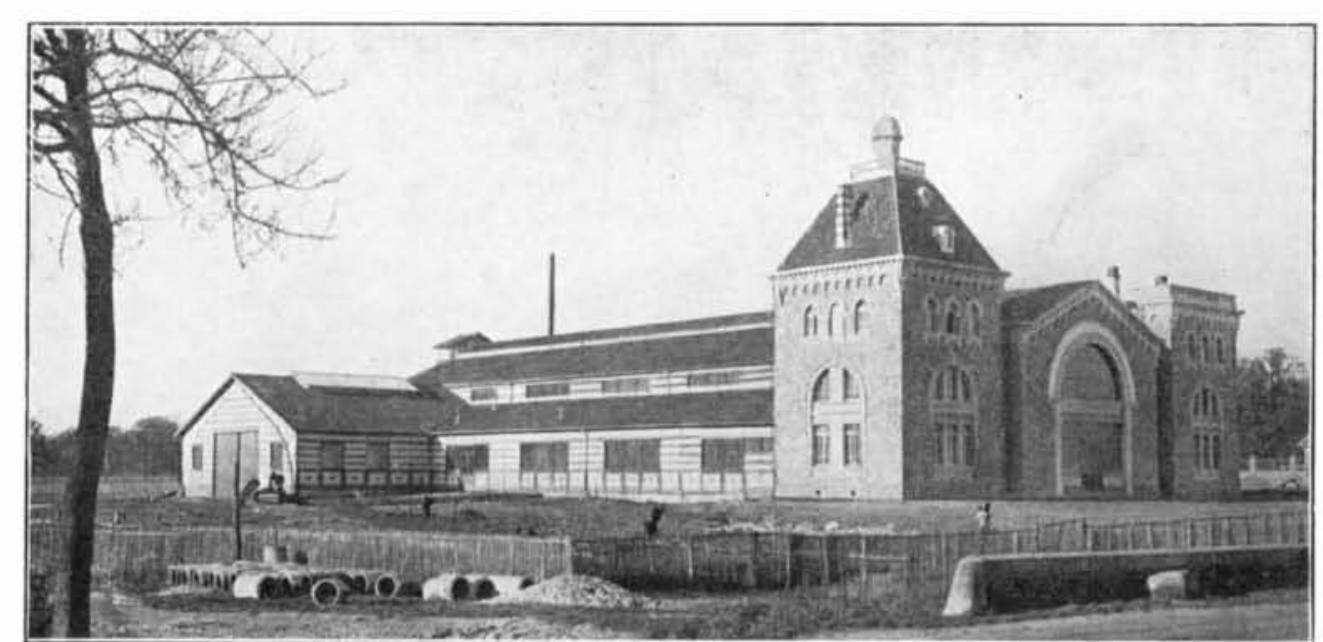

The St. Cyr Aeronautic Institute-Endowed by Henri Deutsch de la Meurthe

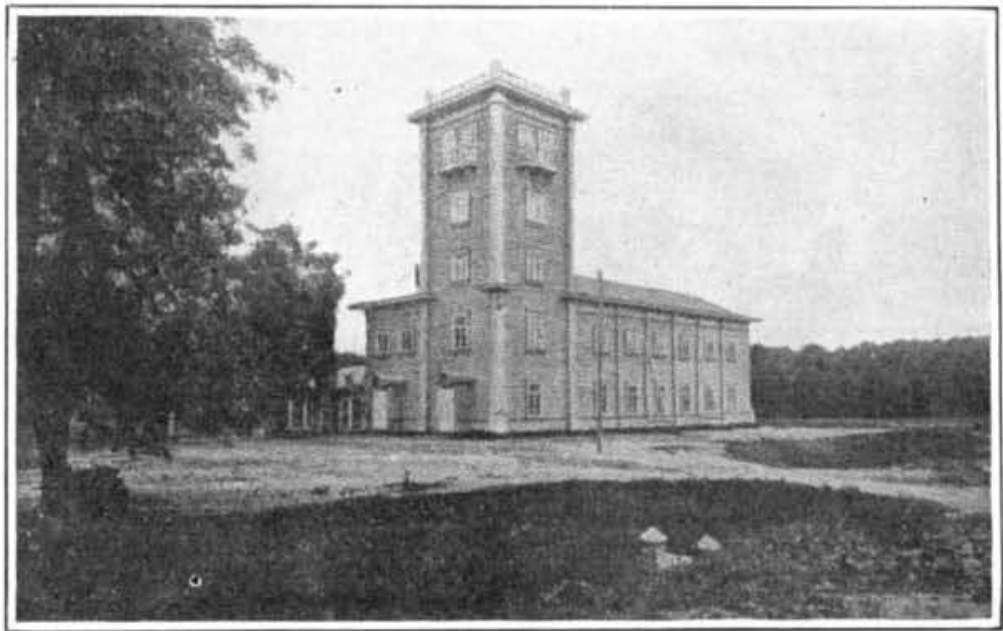

The Aerodynamic Laboratory of Koutchino, Russia. of apparatus, instruments, materials, and models, in fact, by all the facilities of the aerodrome, the showroom, the library, and th. lecture room.

An exact knowledge of aerodynamics can best be acquired in such a laboratory by experimentation with standard scale models in air tunnels such as those used by $\mathrm{M}$. Eiffel and others. In this way reliable data are obtained of the air resistance to be encountered and the efficiency at various velocities, the amount of lift, the effect of varying impact at different angles of attack on the stability, in fact, all the exact data which, reduced to curves and diagrams, enable the engineer to design a machine in a scientific manner. From such data the performance of a new machine can be closely predicated. The performance of the finished product can be verified later as before described.

Much of the research work will be prosecuted at the request of technical men outside of the institution to whom the laboratory should offer, gratuitously as far as possible, its material and personal resources. THE COUNCIL AND ORGANIZATION.

To obtain benefit from these researches it will be necessary to know that they are worth the time and expense, and a body of men, a council or a board of governors, should be authorized to accept or reject requests for this work. This will be a delicate task, but the principal duty of the council should be to establish and to correct, from time to time, a programme of the research work to be executed by the director and his staff, and to co-ordinate the work to the best adhis staff, and to co-ordinate the work to the best ad-
vantage within the limits of the money available. The vantage within the limits of the money available. The
disbursement of the Government funds, however, and the responsibility therefor should be entirely under the director.

With the actual state of aerial navigation and its deficiencies as a guide, it will be the policy of the council to concentrate effort upon such points as seem most important, promising and interesting for the time being.

I do not think there would be any doubt, if we had the laboratory in working order now, but that all questions relating to improvement in stability, automatic control, and safety in general would have the right of way.

The council or board, which in England is called the "Advisory Committee," should be representative of other Government departments than that employing the director, and should be independent of the director and his administrative staff. It might be possible for the director to act as a member of the council, and, if so, it would conduce to harmony and expedition.

The council should not be a large body, but should be composed mostly of specialists of unquestioned ability, men interested in the sane development of aerial navigation in various branches of the Government, and in its useful and safe adaptation to commerce and sport.

Whatever the ability of this council, it should not be allowed to pretend that it has a monopoly. of aeronautic acumen. Many brilliant and worthy ideas may originate outside of the establishment which it will

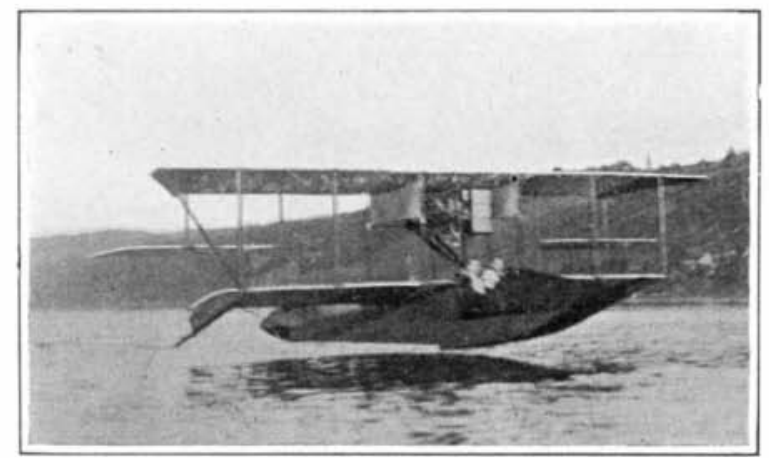

The Latest Curtis Flying Boat, With Glen H. Curtiss and Capt. W. I. Chambers at the Helm. be wise to investigate. And to avoid any possibility of the council being charged with narrow prejudice, it is indispensable that it be not composed entirely of specialists. In a few words, it should comprise representative men who are also learned and technical men, with broad vision and reputation, whose presence will guarantee to industrial investigators that their ideas will be treated in an unpartisan or unbiased spirit. I will not attempt to suggest the composition of this council or board, but it is evident that the army and the navy should each be adequately represented on it.

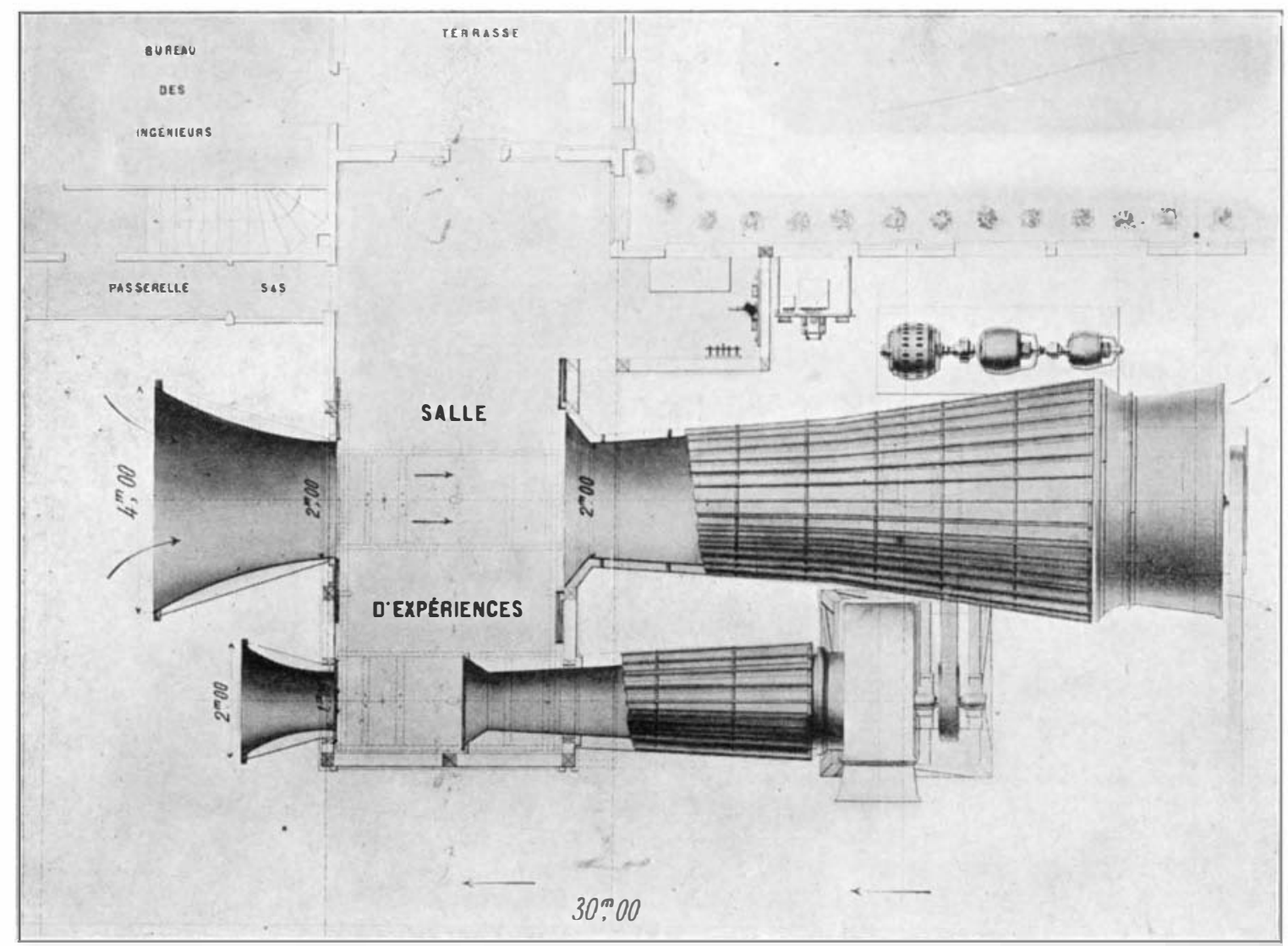

Plan of the New Aerodynamic Laboratory, the Large and Small Wind Tunnels.
ENDOWMENTS, PRIZES, AND REWARDS.

If the laboratory should obtain, in addition to the funds required for prosecuting researches by its staff, any endowments of financial aid in excess of immediat needs (and I am confident it will eventually), it would accomplish useful work by offering prizes and granting rewards for important results achieved outside of the institution. The division of rewards would be one of the functions of the council, and it is possible that this would be one of the best uses of such resources, after the success of the laboratory is assured.

The complete role of an ideal aerodynamic laboratory can be summed up now in a few words in the natural order of establishments: (1) Execution of verification tests by means of nominal fees; (2) facilities to technical men for prosecuting original researches, (3) execution of researches in accordance with a programme arranged by the council; and (4) reward of commendable results accomplished outside of the laboratory. NATURE OF THE PLANT.

Researches and tests can be made on either a large or a small scale, preferably on both.

The use of small models can be made prolific in results because of the comparatively small cost, pro-$$
\text { . }
$$

tion into the full-sized products. For model work a large plant is unnecessary. M. Eiffel has done very valuable work in a very small establishment.

Certain classes of tests with large models, such, for example, as the block test of propellers, do not require much space. But the conditions are altered when such tests are made on a machine in motion. These more difficult tests are absolutely indispensable, and very important to the usefulness of an official laboratory. Experiments and tests with small models being comparatively inexpensive, private establishments ofton parative inexpensive, private establishents o draw conclusions from their results, we are obliged to

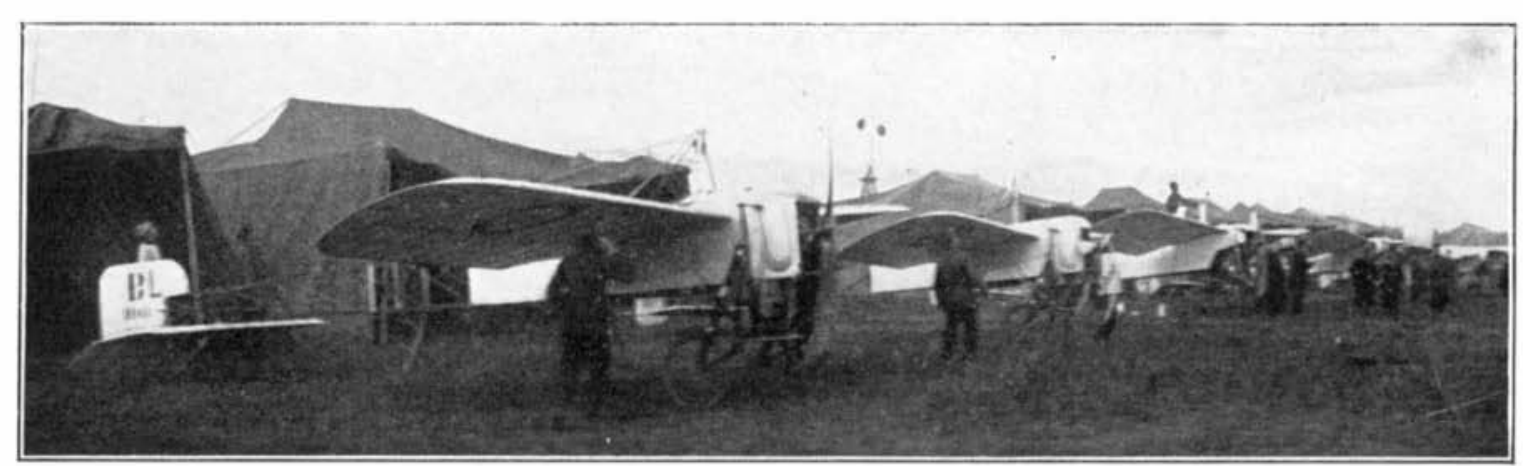

Partial View of the Military Aeroplane Review at Villacoublay, France, in Which Seventy-two Aeroplanes Took Part. 
admit that the laws of comparison with full sized machines are debatable the world over. Comparison are sensibly true between small surfaces and large surfaces that have been extended proportionately to the square of the linear dimensions, even to surfaces five or ten times larger, but when we pass to much larger surfaces, as we are obliged to, we are forced to adopt formulas with empirical coefficients about which there is indefinite dispute.

The difficulty can be overcome only by precise ex periments upon large surfaces, and such experiments, whatever the manner in which they are performed, will be costly. If privately executed the financial returns would not cover the cost.

The laboratory should comprise, therefore, two distinct parts, one devoted to experiments on small scal models, and the other to experiments on surfaces of large dimensions. But in both parts precise and thorough work is necessary.

When we have studied separately each element, of an aeroplane, for example, it will be necessary to test the complete apparatus. An aerodrome annex is therefore necessary, or, at least, the laboratory should be located in proximity to an aerodrome of which it can make use. In order that the observations may not only be qualitative but quantitative, it will be necessary to follow all the movements of the complete machine, to know at each instant the speed, the inclination, the thrust of the propellers, the effective horse-power, and, in fact, to conduct a true open-air laboratory for the craft after the manner of certain tests that have been prolific of results in France.

The English have established close relations between the Royal Air Craft Factory and their laboratory, the functions of the former being the reconstruction and repair of aeroplanes, the test of motors, and the instruction of mechanics.

LOCATION OF THE LABORATORY.

The location of the model testing plant, the headquarters of the administration staff, requires comparatively small space, and there is no reason why it should be remote from a city or from intellectual and material resources. It is advantageous to have it easy of access to many interested people who are not attached to it. The location of the open-air laboratory should obviously be at an aerodrome, as near as may be con venient to the model-testing plant or headquarters. Close proximity of the two parts is desirable, but no necessary. The high price of land near a large city obliges the aerodrome annex of foreign plants to be located at a distance, but we are fortunate in having here, at Washington, ideal conditions for the location of both parts. The model laboratory should obviously be located on the site of Langley's notable work at the Smithsonian Institution, where the nucleus, an extensive library of records and a certain collection of instruments, are still available. The National Museum is also an ideal location for the historical collection of models that will result.

No more ideal location for the annex, the open-air laboratory or aerodrome, exists in all the world than that afforded by the, as yet undeveloped, extension of Potomac Park. This is Government property which is of doubtful utility as a park only, but which would be of immense utility and interest as a park combined with a scientific plant of the character under consideration. There is no reason why the public should be excluded from such a practice field, but there is much to recommend that it be open to the public under proper regumend that it be open to the public under proper regu-
lations as to the traffic, especially on occasions of certain tests or flights of an educational value. It is of sufficient area, about one square mile. It is about two miles long, and it is almost entirely surrounded by broad expanses of water. While convenient of access, it is so situated that the public may be readily excluded when tests of a dangerous character are in process of execution. of a dangerous character are in process of execution.
The fine driveways that will be required as a park will offer excellent facilities for the practice work of the aerodrome, and for the moving test cars that should be supplied.
One of the most attractive features of this location is the advantage it offers as an ideal aerodrome for both the army and the navy, for both land and water flying, and the opportunity it affords for co-operation in all branches of the work of instruction and experimentation. Furthermore, it is near to the shop facilities of the Navy Yard, the accommodations of the Washington Barracks, the conveniences of the various Government hospitals, and it would doubtless add to the information and interest of the nearby War College Staff, and the General Board of the Navy. This location would enable our statesmen in Congress, and a great number of officials in all departments, to keep in touch at first hand with the progress of aeronautics, with the quality of the work done, and with the manner in which the money appropriated was being expended. The educational facilities afforded by the work and by the lectures would be invaluable to the course of
instruction for army, navy, and civil students of aeronautics.

As Washington is a Mecca for business people of all parts of the country, a laboratory located here would be convenient in a commercial sense, especially in view of its southerly location, which renders the open aerodrome available for use throughout the greater part of the year. The only objection that I can see to the Potomac Park extension is that the ground will require a considerable clearing. It is now, principally, a vast cornfield.

\section{THE APPARATUS NEEDED.}

It is useless to discuss here the various instruments and methods which have been a source of some dispute abroad. All have some good feature, but time has shown where some of the cumbersome and unnecessary installations may be eliminated to advantage, and where others may be improved. The new plant of $M$. Eiffel at Auteuil may be regarded as a model for the wind tunnel Auteuil may be regarded as a model for the wind tunne
and the aerodynamic balance. A duplicate of that plant alone would be of inestimable value. The last volume published by $\mathrm{M}$. Eiffel is a forcible example of the value of his discoveries, by this method, with respect to the angle of incidence, and the displacements of the center of pressure. It seems to merit the utmost confidence, although the details of his installation differ from those at Chalais, at Koutchino, at the Italian laboratory, and others. This method permits of testing the resistance of body structures, the sustaining powe of surfaces, the tractive power of propellers, and the influence of transverse or oblique currents. If a "free drop" apparatus at uniform speed be regarded as indispensable to obtaining the coefficients of air resistance to solid bodies of different shapes, it is possible that the interior of the Washington Monument could be used to advantage, as was the Eiffel Tower, withou disturbance of the main function of that noble structure. This would be an excellent place from which to observ the stability or action of falling models cast adrift at an altitude of 500 feet under varying atmospheric con ditions. The free drop of full-sized models would, of course, require the use of kites or captive balloons.

The moving car previously referred to for tests of verification would be the most useful open-air plant, and would soon repay the outlay required by the value of the information obtained from its use. A miniature duplicate of this method for preliminary tests on models with a wire trolley would be of value in a hall of large dimensions. It would be useful in winter work, but not invaluable.

The track of the open-air vehicle at St. Cyr is to restricted to give the best results. The car cannot circulate continuously at high speed and maintain the speed for a sufficient length of time. An ideal endless track may readily be arranged at the Potomac Park extension, preferably of rectangular form with rounded corners. A railway track would be preferable, but excellent results could be obtained from auto truck run on macadamized roadbeds. Good results could be obtained by the use of suitable hydroaeroplanes or flying boats suitably equipped with instruments.

Whirling tables are useful only when designed of large radius. They belong necessarily to the open-air plant, but unless considerable expense is sacrificed for installation they can serve for reduced models only. I would not recommend their installation until the necessity for their use is clearly demonstrated.

At the aerodrome annex ample facilities should be provided for measuring the wind velocity at various heights and at different points. The convenient installation of recording anemometers, and the employment of kites or captive balloons should be considered.

A branch of the U. S. Weather Bureau could readily be established at the aerodrome here in connection with the investigation of meteorological phenomena affecting the movements of aeroplanes in flight, and as an adjunct to the National Laboratory.

Exactly measured bases and posts of observation are also required, as well as instruments of vision or photographic apparatus, to permit of following machines in their flights, and of preserving the records for study.

One of the most useful installations for recording advanced information is in an actual aeroplane itself equipped with instruments adapted to record, while in flight, much of the information that is desired. Such a machine is already in use in France, and in England. It will be in perfect harmony, and convenient to the laboratory, to obtain all the services of an air-craft factory from the Washington Navy Yard, where facilities already exist for the reconstruction and repair of aeroplanes, the test of motors, and the instruction of mechanics. But this should not be allowed to interfere with our policy of relying upon private industry for the purchase of new machine; for the sake of encouraging the art among private builders.

It will suffice to merely mention the hangars or sheds required, or the local accessories, such as drafting room, office, and minor repair shop. The character and location of these present no difficulties, but they should not be made the principal part of the institution as they are in several elaborately equipped foreign laboratories. The power plant, however, is a subject for careful consideration, and the economy effected by M. Eiffel in his new installation at Auteuil is worthy of study.

$$
\cos \mathrm{T}
$$

I have seen estimates varying from $\$ 250,000$ to $\$ 500,000$ for such a plant, but inasmuch as $\$ 100,000$ with an annuity of $\$ 3,000$ donated by M. Henri Deutsch de la Meurthe to the University of Paris for the establishment of the Aeronautical Laboratory at St. Cyr seems to have been sufficient for a very creditable though somewhat deficient plant, I will venture an opinion that $\$ 200,000$ would be sufficient in our case. Although the same plant would cost more in this country, I assume that some of the buildings required are already available at the Smithsonian Institution. If located elsewhere the cost would be considerably more than the sum named.

\section{COMMISSION RECOMMENDED.}

Inasmuch as more definite information regarding the actual cost of a dignified and creditable but modest and sufficient installation should be obtained, and as the details of the plan, the scope, the organization, and the location of such an important undertaking should not be left to the recommendations of one man, a commission or board should be appointed to consider and report to the President, for recommendation to Congress, on the necessity or desirability for the establishment of a national aerodynamic laboratory, and on its scope, its organization, the most suitable location for it, and the cost of its installation.

It is hoped that the preceding outline is sufficiently definite to start the machinery of legislation necessary to expedite the acquirement of such an institution. The plant is needed not only to further the interests of science and national preparedness, but to further the interests of humanity. By such means we can best hasten the production of safety and efficiency. in air craft, and reduce our percentage of martyrs to aviation, which is now greater here than in any other country. Aviation has come to stay, and I believe pular sentiment is in favor of making it safe.

\section{The Government and Our National Timber}

\section{A Defense of the Present Policy}

THE crucial test of public ownership and management of forests in the United States will be the power to resist an unintelligent demand for the Government to sell timber cheap, on the supposition that this will enable the public to buy lumber cheap.

The Government is now being criticised for not selling National forest timber cheaper and faster. It is charged with virtually aiding private timber monopolies to gouge the public. In point of fact it is doing just the reverse.
The Government could not materially lower the cost by half the price charged for timber cut on the National forests. But it could enable many lumbermen to grow rich fast. Also, it could and would prepare the way for a timber monopoly later that would be a monopoly with a vengeance. Incidentally, it would promote wanton and great waste of valuable timber, both on and off the National forests, by operators who would merely skim the cream, and it would permit the extra cost of bad management to be saddled on the public.
HOW TIMBER IS SOLD.

The average price at which National forest timber was sold on the stump by the Government last year was $\$ 2$ per thousand.

The Forest Service spent thousands of dollars advertising its timber. It seeks purchasers by every means in s power. It sold last year the equivalent of about million board feet of timber in all forms-for lumber. mine props, fuel, posts, and many other uses.

The cut, for lumber alone, of the entire United States was between 40 and 45 billion feet. 